\title{
Der CFO als IT-Botschafter
}

\author{
Ein gut funktionierendes Finanzwesen eines Unternehmens braucht eine entsprechende \\ technische Unterstützung. CFOs müssen sich deshalb mit neuen IT-Trends auseinandersetzen.
}

Was sind die wichtigsten Eigenschaften eines modernen, Technologie-gestützten Finanzwesens in Unternehmen? Eine internationale Studie der IT-Unternehmen Oracle und Accenture, an der 1.275 CFOs, Top Manager aus dem Controlling und Abteilungsleiter aus anderen Fachbereichen teilnahmen, gibt Aufschluss. Die sechs wichtigsten Ergebnisse der Studie fasst Oracle wie folgt zusammen:

- CFOs sind Botschafter der Technologie, aber zwischen Anspruch und Wirklichkeit klafft eine Lücke.

- Neue Fähigkeiten und Analysemöglichkeiten sind notwendig, damit eine moderne Finanzabteilung ihre Aufgaben erledigen kann.

- CFOs streben nach der Automatisierung von Prozessen, der Konsolidierung von Systemen und nach Reports in Echtzeit. Aber hier ist noch viel zu tun.
- Technologien wie Big Data, Cloud, mobile und soziale Medien sind inzwischen so ausgereift, dass sie Unternehmen dazu zwingen, ihre Strategien im Umgang mit Informationstechnologie zu überdenken.

- Das Top Management unterstützt die Technologie-Vision.

- CFOs setzen auf die Cloud, wenn es um die Modernisierung des Finanzwesens geht.

Es sind also Fortschritte hin zu einem produktiveren und effizienteren Technologie-basierten Finanzwesen zu verzeichnen. Handlungsbedarf gibt es vor allem noch bei der Datenqualität. Viele Firmen verlassen sich laut der Studie bei ihren Entscheidungen auf veraltete Daten. Wenn Daten aus vielen unterschiedlichen Systemen konsolidiert werden sollen, stellt sie das vor große Herausforderungen. Mehr dazu auf: SfP www.springerprofessional.de/5170976

\section{Erfolg
durch Agilität!}
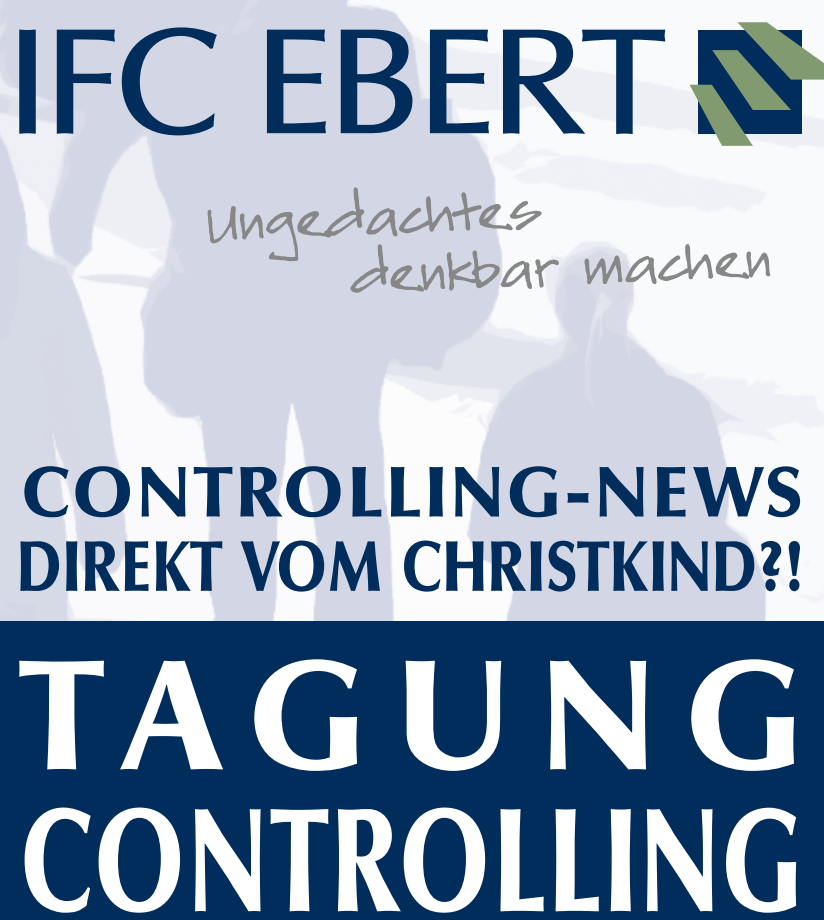